\title{
Beton Ağırlıkıı Barajların Simbiyotik Arama Algoritması ile Optimizasyonu
}

\author{
Kemal SAPLIOĞLU ${ }^{1 *}$, Erdem ÇOBAN ${ }^{2}$, Fatih Ahmet ŞENEL ${ }^{3}$, Soner UZUNDURUKAN ${ }^{1}$

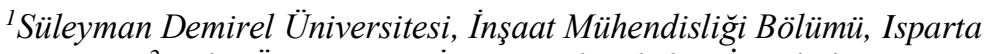 \\ ${ }^{2}$ Haliç Üniversitesi, İnşaat Mühendisliği, İstanbul \\ ${ }^{3}$ Süleyman Demirel Üniversitesi, Inşaat Mühendisliği Bilgisayar Mühendisliği, Isparta \\ (ORCID: 0000-0003-0016-8690) (ORCID: 0000-0003-1918-7277) \\ (ORCID: 0000-0002-4526-7273) (ORCID: 0000-0003-4080-6642)
}

\begin{abstract}
$\ddot{O} \mathbf{z}$
Artan nüfus ve sanayileşme suya olan ihtiyacı hızlıca arttırmaktadır. Bu artış miktarı projelerin boyutlarını da arttırmaktadır. Klasik yöntemlerle yapılan projelendirmelerde maliyetler oldukça yüksek çıkabilmektedir. Bu çalışmada su kaynakları projelerinin en önemlilerinden olan beton ağırlıklı barajların Simbiyotik Arama Algoritması (SOS) kullanılarak optimum boyutlarının bulunması amaçlanmıştır. Çalışmada baraj yükseklikleri ve deprem ivmeleri değişimi ile maliyet artışları da ve bu artışların oranları hesaplanmıştır. Elde edilen sonuçlar grafikler ve tablolar ile yorumlanarak yorumlanmıştır. Ayrıca çalışmada her girdi parametresi için modelleme yapabilecek bir program da geliştirilmiştir.
\end{abstract}

Anahtar kelimeler: Simbiyotik Arama Algoritması, Beton ağırlık barajlar, Optimizasyon.

\section{Optimization of Concrete Gravity Dams by Symbiotic Search Algorithm}

\begin{abstract}
Increasing population and industrialization increases the need for water. This increase also increases the size of the projects. Costs can be quite high in the projects made with classical methods. In this study, it is aimed to find optimum dimensions of concrete dams which are one of the most important water resource projects by using Symbiotic Search Algorithm (SOS)., changes in dam heights and earthquake accelerations and cost increases and the rates of these increases were calculated. The results are presented with graphs and tables. In addition, it has been also developed in a program that can make modeling for each input parameter.
\end{abstract}

Keywords: Symbiotic Search Algorithm, Concrete weighted dams, Optimization.

\section{Giriş}

Günümüzde artan nüfus ve sanayileşme suya olan talebi arttırmaktadır. Bu nedenle oluşturulan projelerin boyutlarınıda arttırmaktadır. Boyut artışları ise projelendirme aşamasında bir takım zorluklarla karşılaşmamıza sebep olmaktadır. Bu zorunluluklar özellikle su yapıları gibi çok büyük maliyetlere sahip yapı hizmetlerde çok daha fazla önemli hale gelmektedir. Yapımında kullanılan malzemenin fazla ve maliyetli olması bakımından optimum fayda elde etme gayretinde bulunmamızı gerekmektedir. Gelişen teknoloji ve bilgi birikimimizi bu istikamette kullanarak maksimum verimde yapılar inşa etmek bilim insanlarının amaçları arasında olmalıdır. Endüstriden yapı sektörüne, havacılıktan pazarlamaya kadar geniş bir yelpazede aynı kaygı göz önünde bulundurulmaktır. Endüstri çağından sonra hızla gelişen birçok sektörün çevre ve doğaya vermiş oldukları zararlı etkilere karşı duyarlılığın artması gerekmektedir. Önceki yaklaşımların aksine geri dönüşüm, tekrar kullanma, daha uzun ömürlü ve dayanıklı tasarımlar yapma bunlar için de bilimi ve teknolojiyi daha fazla ve efektif olarak kullanmak zorunlu hale gelmiştir.

*Sorumlu yazar: kemalsaplioglu@sdu.edu.tr

Geliş Tarihi: 13.01.2020, Kabul Tarihi: 19.03.2020 
İnşaat mühendisliğinde salt tasarım değil aynı zamanda kullanılan malzeme, mobilizasyon, uygulama, işçilik ve proje planlama konularında ekonomik çıktılar elde etmek adına bütün değişkenler ele alınarak maliyeti en aza indirip maksimum fayda sağlamak adına birçok konu göz önüne alınmalı ve tüm alternatifler gerekirse denenmelidir.

Ülkemizin su potansiyeli ve yükselti farklarından dolayı barajlar, en fazla uygulanan ve fayda sağlayan su yapılarının başında gelmektedir. Sulama, enerji, ulaşım, içme suyu vb. birçok amaca hizmet eden barajlar proje ve tasarım maliyetleri bakımından büyük bir yer teşkil etmektedirler. Bu bakımdan baraj tasarım ve projelerinde yapılacak tasarruflar ülke ekonomisi adına çok büyük bir katk1 sağlayacaktır. Enerji yönüyle dışa bağımlılığının azalması ve kendi öz kaynaklarımızı kullanarak baraj projelerinin ülkemizde çok fazla olması bunun önemini kat ve kat arttırmaktadır. En uygun tasarımların yapılması, son dönemde üzerinde fazlaca çalışılan optimizasyon yöntemlerle ve bu yöntemlerin geliştirilen bilgisayar programlarıyla desteklenmesiyle çok daha kolay olmaktadır.

Optimizasyon genel olarak klasik (matematiksel) [1,2] ve evrimsel (meta-sezgisel) [3-5] optimizasyon olarak iki gruptan oluşur. Klasik optimizasyon yöntemleri ile türevlenebilen fonksiyonlara sahip problemlerin çözümünde kullanılırlar. Türev işlemlerinin hızlılığından dolayı kısa sürede daha kesin sonuçlar alınabilir. $\mathrm{Bu}$ yaklaşım deterministik bir yaklaşım olup bu avantajlarının yanında gündelik hayatta çok az uygulanabilirliği mevcuttur. Meta sezgisel yöntemler doğanın ve doğada yaşayan canlıların davranışları gözlemlenerek geliştirilerek rassallık ilkesine göre çalışan optimizasyon çeşididir.

Yapının ekonomisi ve güvenliği, tasarımdaki kilit noktalardır. Kemer ve ağırlık barajlar gibi en uygun baraj tasarımları için birçok girişimde bulunulmuştur. Bu çalışmada kullanılacak olan metasezgisel optimizasyon yöntemlerinin kullanımı ile ilgili birçok çalışma bulunmaktadır. Khatibinia ve Khosravi [6] sıvı-yapı etkileşimini dikkate alarak yerçekimi arama algoritmasını kullanarak yerçekimi barajının şekil optimizasyonunu gerçekleştirmişlerdir. Kshirsagar [7], Hindistan'ın Maharastra şehrinde bulunan Tilari ağırlık barajının Hint tasarım kriterlerine göre deprem yoğunluğundaki değişimin stabilitesine etkisini araştırmıştır. Salmasi [8] yerçekimi barajının tasarım optimizasyonu için genetik algoritma kullanmıştır. Deepika ve Suribabu [9] Hint tasarım kriterlerine göre beton yerçekimi barajının [10] optimal tasarımı için diferansiyel evrim algoritmasını kullanmışlardır. Kemer barajlarının optimum tasarımında da pek çok araştırma yapılmıştır [11-14]. Optimizasyon yöntemleri ile baraj tipleri [15] ve şekil farklılıklarının [16] maliyet üzerine etkileri de araştırılmıştır. Ayrıca optimizasyon algoritmaları arasındaki farkların barajlar üzerinden yapıldığı çalışmalarda mevcuttur [17].

$\mathrm{Bu}$ çalışma, stabilite ve temel gerilme kısıtlamaları empoze eden bir ağırlık barajının şekil optimizasyonunu sunmaktadır. Bir ağırlık barajı, büyük miktarda beton malzemeden oluşan büyük ölçekli bir hidrolik yapıdır. Bu nedenle, optimum tasarım, baraj kesitindeki küçük değişikliklerin büyük miktarda beton hacmi tasarrufuna yol açması nedeniyle maliyet avantajı sağlar. Bu çalışmada beton dolgu barajların simbiyotik organizmalar arama algoritması ile tasarımına ulaşmak hedeflenmiştir. Yapılan çalışmada farklı yükseklikler için maliyet analizi yapılmıştır. Oluşturulan senaryoda yükseklikler değiştirilmiştir.

\section{Materyal ve Metot}

Çalışmada Beton Ağırlık barajlarının SOS (Simbiyotik Arama Algorirması) ile yüksekliğe bağlı optimizasyonu araştııılacaktır. Bu bölümde barajlara etki eden kuvvetler ile kısıt fonksiyonlarının yanı sıra SOS algoritması hakkında bilgiler verilecektir.

\subsection{Beton ağırık barajların stabilite analizleri}

Beton ağırlık barajları, genel olarak hidroelektrik santrallerine su rezervuarı olarak yaygın olarak kullanılan hidrolik yapılardır (Şekil 1). Bu yapılar enine kesitlerinde yamuk biçimlidir ve yerçekimsel davranışlarla (kendi ağırlıkları ve diğerleri gibi) hidrostatik ve taban ve boşluk suyu basıncının sebep olduğu kaldırma basınçlarına karşı dengeyi sağlarlar [18]. Bu nedenle, kesit için uygun bir tasarım bulmak inşaat maliyetlerini önemli ölçüde azaltabilir. 


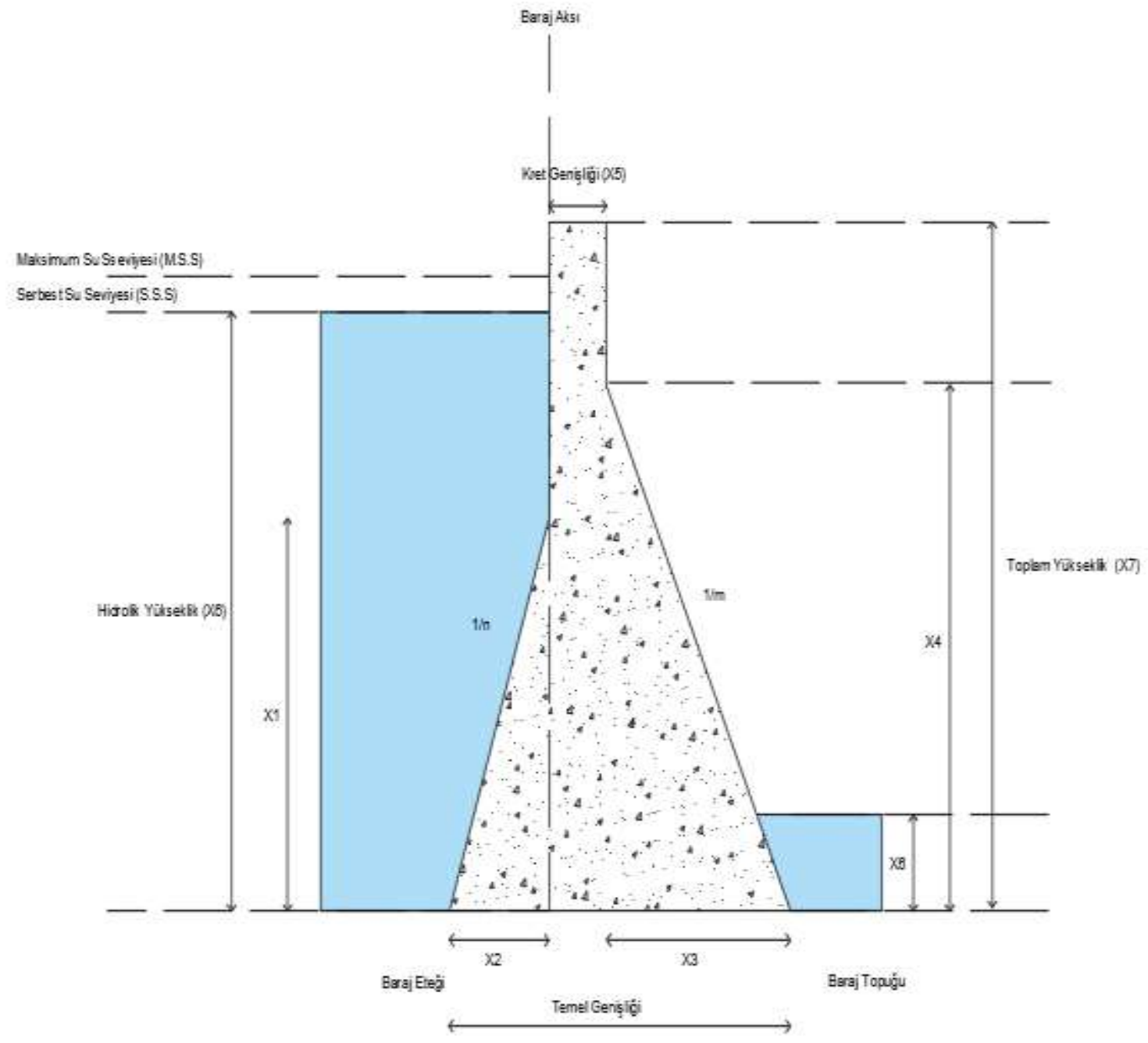

Şekil 1. Beton ağırlık barajları boyutları

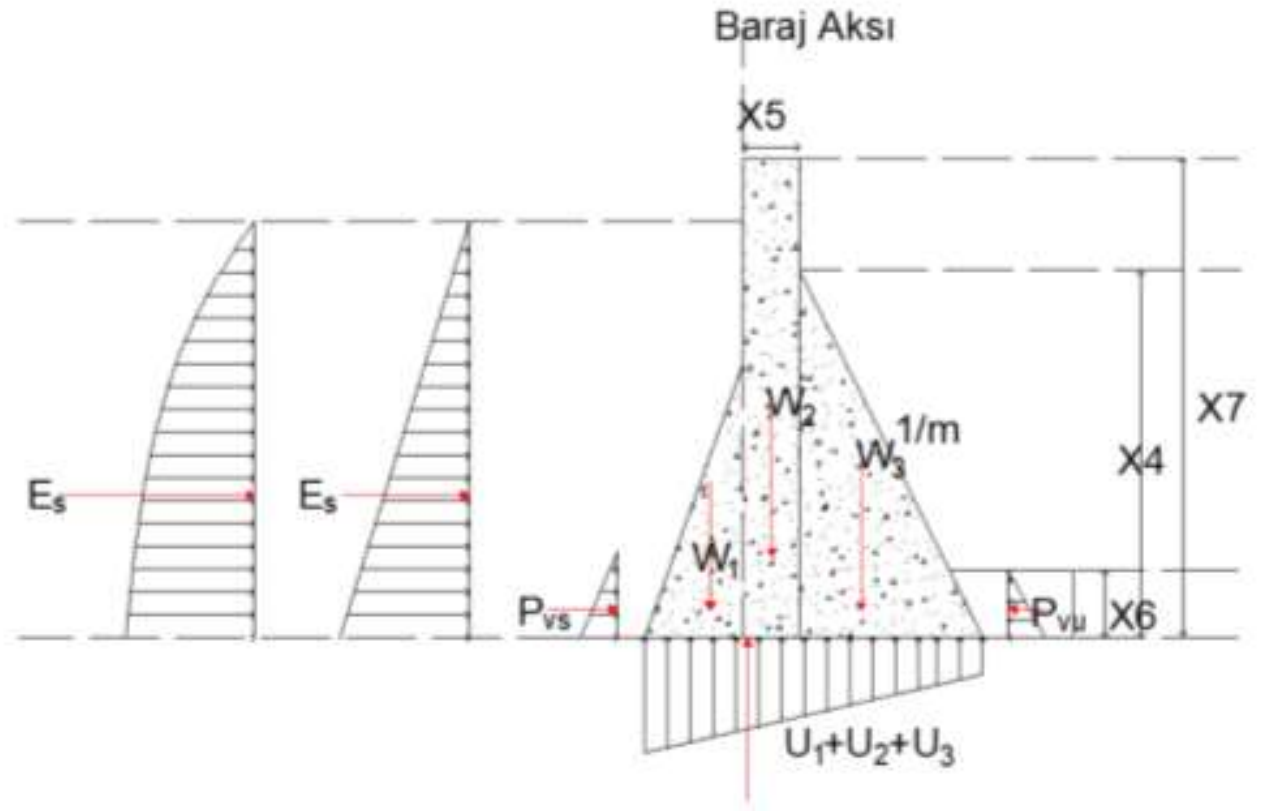

Şekil 2. Beton ağırlık barajlarına etkiyen kuvvetler 
Tablo 1. Baraja etkiyen kuvvetler ve moment kolları

\begin{tabular}{|c|c|}
\hline$W_{1}=\frac{1}{2} \gamma_{c} x_{1} x_{2}$ & $l_{1}=x_{3}+x_{5}+\frac{1}{3} x_{2}$ \\
\hline$W_{2}=\gamma_{c} x_{5} x_{7}$ & $l_{2}=x_{3}+\frac{x_{5}}{2}$ \\
\hline$W_{3}=\frac{1}{2} \gamma_{c} x_{3} x_{4}$ & $l_{3}=\frac{2}{3} x_{3}$ \\
\hline$P_{V_{1}}=\frac{1}{2} \gamma_{w} x_{1} x_{2}$ & $l_{4}=x_{3}+x_{5}+\frac{2}{3} x_{2}$ \\
\hline$P_{V_{2}}=\frac{1}{2} \gamma_{w} x_{2}\left(h-x_{1}\right)$ & $l_{5}=x_{3}+x_{5}+\frac{1}{2} x_{2}$ \\
\hline$P_{V u}=\frac{1}{2} \gamma_{w}\left(m h_{u}\right) h_{u}$ & $l_{6}=\frac{m h^{\prime}}{3}$ \\
\hline$U_{1}=\frac{1}{3} \gamma_{w}\left(x_{2}+d_{g}\right)(h-h u)$ & $l_{7}=x_{3}+x_{5}+\frac{1}{3}\left(2 x_{2}-d_{g}\right)$ \\
\hline$U_{2}=\frac{1}{3} \gamma_{w}\left(x_{2}+d_{g}\right)(h+2 h u)$ & $l_{8}=x_{3}+x_{5}+\frac{1}{2}\left(x_{2}-d_{g}\right)$ \\
\hline$U_{3}=\frac{1}{2} \gamma_{w}\left(x_{3}+x_{5}-d_{g}\right)\left(\frac{h-h u}{3}\right)$ & $l_{9}=\frac{2}{3}\left(x_{3}+x_{5}-d_{g}\right)$ \\
\hline$U_{4}=\gamma_{w}\left(x_{3}+x_{5}-d_{g}\right) h u$ & $l_{1_{-} 0}=\frac{1}{2}\left(x_{3}+x_{5}-d_{g}\right)$ \\
\hline$P_{v_{s}}=\frac{1}{2} * 0,925 \gamma_{w} n h_{s}^{2}$ & $l_{1_{-} 1}=x_{3}+x_{5}+x_{2}-\frac{n h_{s}}{3}$ \\
\hline
\end{tabular}

Burada $m=x_{3} / x_{4}, n=x_{2} / x_{1}, B=x_{5}, H=x_{7}, h=x_{6}, h^{\prime}=h_{m}=x_{6} / 10, h_{w}=1.0$ ve $h_{s}=x_{6} / 10$ Tablo 1'de baraja etkiyen su ve ağırlık kuvvetleri ile moment kollarının uzunlukları verilmiştir. $B=\mathrm{Kret}$ genişliği $B_{1}=$ Baraj taban genişliği, $\mathrm{H}=$ Barajın toplam yüksekliği, h Maksimum rezervuar yüksekliği, $h$ ' Kuyruk suyu yüksekliği, $h_{s}$ Biriken silt yüksekliği, $1 / \mathrm{m}$ mansap yüzü eğimi, $1 / \mathrm{n}=$ memba yüzü eğimi, $d_{g}$ drenaj galerisinin baraj aksına olan uzaklığıdır (Şekil 2).

Tablo 2. Baraja etkiyen deprem kuvvetleri ve moment kolları

\begin{tabular}{|c|c|}
\hline$E V_{1}=\alpha_{v} W_{1}$ & $l_{11}=x_{3}+x_{5}+\frac{1}{3} x_{2}$ \\
\hline$E V_{2}=\alpha_{v} W_{2}$ & $l_{12}=x_{3}+\frac{x_{5}}{2}$ \\
\hline$E V_{3}=\alpha_{v} W_{3}$ & $l_{13}=\frac{2}{3} x_{3}$ \\
\hline$E V_{4}=\alpha_{v} P_{v_{1}}$ & $l_{14}=x_{3}+x_{5}+\frac{2}{3} x_{2}$ \\
\hline$E V_{5}=\alpha_{v} P_{v_{2}}$ & $l_{15}=x_{3}+x_{5}+\frac{1}{2} x_{2}$ \\
\hline$E V_{6}=\alpha_{v} P_{v u}$ & $l_{16}=\frac{m h^{\prime}}{3}$ \\
\hline$P_{H}=\frac{1}{2} \gamma_{w} h^{2}$ & $l_{17}=\frac{h}{3}$ \\
\hline$P_{H u}=\frac{1}{2} \gamma_{w}(h u)^{2}$ & $l_{18}=\frac{h^{\prime}}{3}$ \\
\hline$P_{H_{s}}=\frac{1}{2} 0,36 \gamma_{w} h_{S}^{2}$ & $l_{19}=\frac{h_{s}}{3}$ \\
\hline \multicolumn{2}{|l|}{$K_{A}=\operatorname{tg}^{2}\left(45-\frac{\phi}{2}\right)$} \\
\hline$P_{W}=2 \gamma_{w} h_{w}^{2}$ & $l_{20}=h+\frac{3}{8} h_{w}$ \\
\hline$E H_{1}=\alpha_{H} W_{1}$ & $l_{21}=\frac{x_{1}}{3}$ \\
\hline$E H_{2}=\alpha_{H} W_{2}$ & $l_{22}=\frac{H}{3}$ \\
\hline$E H_{3}=\alpha_{H} W_{3}$ & $l_{23}=\frac{x_{4}}{3}$ \\
\hline$P_{e} H=0,726 p_{e H} h^{3}$ & $P_{e H^{\prime}}=0,726 p_{e H^{\prime}} h^{\prime}$ \\
\hline$p_{e} H=C_{m} \alpha_{H} \gamma_{w} h$ & $p_{e H^{\prime}}=C_{m} \alpha_{H^{\prime}} \gamma_{w} h^{\prime 3}$ \\
\hline$M_{e H}=0,299 C_{m} \alpha_{H} \gamma_{w} h^{3}$ & $M_{e H^{\prime}}=0,299 C_{m} \alpha_{H^{\prime}} \gamma_{w} h^{3}$ \\
\hline
\end{tabular}




$$
\begin{aligned}
& \sigma_{p D}=\sigma_{y D} \sec ^{2} \phi_{D}-\left(p_{H}^{\prime}-p_{e H^{\prime}}^{\prime}\right) \tan ^{2} \phi_{D} \\
& \sigma_{y D}=\frac{\sum F_{V}}{B_{1}}\left(1+\frac{6 e}{B 1}\right) p_{H}^{\prime}=\gamma_{w} h^{\prime} \\
& \sigma_{p U^{\prime}}=\sigma_{y U} \sec ^{2} \phi_{U}-\left(p_{H}^{\prime}+p_{e H^{\prime}}^{\prime}\right) \tan ^{2} \phi_{U} \\
& \sigma_{y D}=\frac{\sum F_{V}}{B_{1}}\left(1-\frac{6 e}{B 1}\right) p_{H}=\gamma_{w} h \\
& e=\frac{B_{1}}{2}-\underline{x} \\
& \underline{x}=\frac{\sum M_{R}-\sum M_{D}}{\sum F_{V}} \\
& \tau_{x y D}=\left[\sigma_{y D}-\left(p_{H}^{\prime}-p_{e H^{\prime}}^{\prime}\right)\right] \tan ^{2} \phi_{D} \\
& \tau_{p U}=\left[\sigma_{y U}-\left(p_{H}+p_{e H}^{\prime}\right)\right] \tan ^{2} \phi_{U} \\
& F S F=\frac{\sum V}{\sum U} \\
& F O S=\frac{\mu \sum F_{V}}{\sum F_{H}}
\end{aligned}
$$

Gerilme Kisıtlamaları

$g_{1}(x)=\sigma_{p D}-\sigma_{c} \leq 0$

$g_{2}(x)=\sigma_{p U}-\sigma_{c} \leq 0$

$g_{3}(x)=\sigma_{x y D}-\sigma_{c} \leq 0$

$g_{4}(x)=\sigma_{x y U}-\sigma_{c} \leq 0$

Dayanım Kısitlamaları

$g_{5}(x)=1,5-F O S \leq 0$

$g_{6}(x)=3-S F F \leq 0$

$M_{R}$ Baraj topuğunda meydana gelen koruyucu moment, $M_{O}$ Baraj topuğunda meydana gelen devirici moment, $\sum F_{V}$ baraj a etkiyen toplam düşey kuvvetler, $\sum F_{H}$ Baraj a etkiyen toplam yatay kuvvetler, q temelde izin verilen kayma gerilmesi, $\sigma_{c}$ Betonda izin verilen basınç dayanımı, $\gamma_{c}$ Baraj malzemesinin özgül ağırlığı, $\gamma_{w}$ suyun özgül ağırlığı, $\mathrm{Nu}$ sürtünme katsayısı, $V_{w}$ rüzgar hızı, e baraj kesitinin itme kuvvetinin dışsallığ $1, \mathrm{f}=$ barajın memba tarafına feç uzaklığı, $\alpha_{H}, \alpha_{V}$ Yatay ve Düşey sismik katsayılar, $P_{e H}, P_{e H}, P_{V_{1}}, P_{V_{2}}, P_{V_{3}}$ Kafa ve kuyruk su basıncı kuvvetlerinin yatay ve düşey bileşenleri, $U_{1}, U_{2}, U_{3}, U_{4}$ Yükselme basınç yüksekliği, $P_{H_{S}}, P_{V_{S}}$ Silt basınç kuvvetinin yatay ve düşey bileşenleri, $P_{W}$ Rezervasyondaki sudan kaynaklı oluşan basınç kuvveti, $W_{1}, W_{2}, W_{3}$ Barajın kendi ağırlığı, $M_{e H}, M_{e H}=P_{e H}, P_{e H}$, 'dan kaynaklı oluşan moment kuvvetleri göstermektedir.

Tablo 1 ve Tablo 2'deki denklemler ile Denklem 1-16 arasındaki kısitlama fonksiyonları kullanılarak hacim fonksiyonunu minimum yapacak boyutlar aranmaktadır. 


\subsection{Simbiyotik organizmalar arama algoritması}

Bir probleme en uygun çözümü bulmak için son yıllarda sezgisel yöntemler yaygın olarak kullanılmaktadır. Sezgisel yöntemler en iyiye çok yakın çözümler sunan, çözüm süresini oldukça kısaltan yöntemlerdir. Gerçek hayatta her gün kullandığımız bu yaklaşımlar genel olarak doğadaki olaylardan esinlenir $[18,19]$.

Her ne kadar yalnız yaşayan organizma türleri olsa da güvenlik ve yardım gibi konular nedeniyle organizmalar çoğunlukla ortak bir yaşamı paylaşırlar. Bazı durumlarda zorunlu bir ortak yaşam olabildiği gibi, organizmaların çıkarları için kendileri de ortak bir yaşamı tercih etmektedirler. Organizmalar arasındaki bu birlikte yaşam üç farklı şekilde gerçekleşebilmektedir. Bunlar; karşılıklı fayda birlikteliği (mutualizm), tek taraflı birliktelik (kommensalizm) ve asalaklık (parazitizm)'dir.

Simbiyotik Organizmalar Arama algoritması (SOS), Cheng ve Prayogo tarafindan 2014 yılında geliştirilmiş güçlü bir sezgi ötesi optimizasyon algoritmasıdır [21]. SOS, doğada yaşayan organizmaların hayatta kalmak için birbirleri ile olan etkileşimlerinden esinlenilerek geliştirilmiş ve literatürde farklı problemlerin çözümünde kullanılmıştır [22,23]. SOS başlangıçta bir grup organizmanın rasgele oluşturulduğu bir ekosistem ile başlatılmaktadır. Her bir organizma aday çözümleri temsil etmekte ve uygunluk değerleri adaptasyon derecelerini ifade etmektedir. Başka diğer optimizasyon algoritmalarında da olduğu gibi, SOS algoritmasında da organizmaların yaşamlarını sürdürebilmesi için biyolojik etkileşim adımları bulunmaktadır. SOS algoritması mutualizm, kommensalizm ve parazitizm adımları olmak üzere üç aşamadan oluşmaktadır.

Mutualizm adımında, birliktelik kuran organizmaların her ikisinin de karşılıklı olarak fayda elde ettikleri adımdır. Ekosistemdeki $i$. organizma $\left(X_{i}\right)$ ile ekosistemden rasgele seçilen $j$. organizma $\left(X_{j}\right)^{\prime}$ nın fayda sağlayacakları bir ilişkinin kurulduğu aşamadır. Bu aşamada $X_{i}$ ve $X_{j}$ organizmaları için yeni aday çözümler üretilmektedir. Eşitlik 17, 18 ve 19'da gösterildiği şekilde aday çözümler oluşturulmaktadır.

$$
\begin{gathered}
X_{i}^{\prime}=X_{i}+\operatorname{rand}(0,1) *\left(X_{\text {eniyi }}-M V * B F_{1}\right) \\
X_{j}^{\prime}=X_{j}+\operatorname{rand}(0,1) *\left(X_{\text {eniyi }}-M V * B F_{2}\right) \\
M V=\frac{X_{\mathrm{I}}+X_{j}}{2}
\end{gathered}
$$

Burada, $B F_{1}$ ve $B F_{2}$ katsayıları sırasıyla $i$. ve $j$. bireylerin ilişkiden elde edeceği fayda faktörünü ifade etmektedir. $B F_{1}$ ve $B F_{2}$ katsayıları 1 veya 2 olarak rasgele seçilmektedir. $M V$ değeri mutual_vektör olarak adlandırılmakta ve organizmalar arasındaki ilişki karakteristiğini ifade etmektedir. Mutualizm adımında üretilen yeni aday bireylerinin $\left(X_{i}^{\prime}\right.$ ve $\left.X_{j}^{\prime}\right)$ uygunluk değerleri eğer eski bireylerin $\left(X_{i}\right.$ ve $\left.X_{j}\right)$ uygunluk değerlerinden daha iyi ise, yeni aday bireyler ile eski bireyler yer değiştirmektedir. $X_{\text {eniyi }}$ değeri ise en iyi adaptasyon sağlamış olan bireyi temsil etmektedir.

SOS algoritmasının kommensalizm adımında, ekosistemdeki organizmalardan biri fayda sağlarken diğeri herhangi bir fayda veya zarar sağlamamaktadır. Ekosistemdeki bir $X_{i}$ organizmasına fayda sağlayacak $X_{j}$ organizması rasgele olarak seçilmektedir. Denklem 20'de gösterildiği gibi $X_{i}$ organizmasının yeni aday çözümü hesaplanmaktadır.

$$
X_{i}^{\prime}=X_{i}+\operatorname{rand}(-1,1) *\left(X_{\text {eniyi }}-X_{j}\right)
$$

Denklem 18 'den görüldüğü üzere $X_{j}$ organizması hiçbir şekilde etkilenmemektedir. $X_{i}^{\prime}$ yeni aday organizmanın uygunluk değeri daha iyi olursa, mevcut $X_{i}$ organizması yeni aday organizma ile değiştirilerek bu adım gerçekleştirilir.

Parazitizm aşamasında bir organizma diğer organizma tarafından zarara uğratılmaktadır. $X_{i}$ organizmasının bazı parametrelerinde rasgele değişiklikler yapılarak $X_{i}$ organizmasının paraziti $\left(P_{X_{\mathrm{I}}}\right)$ oluşturulmaktadır. Daha sonra ekosistemden zarara uğratılacak olan organizma $\left(X_{j}\right)$ rasgele olarak seçilmektedir. $P_{X_{\mathrm{I}}}$ ve $X_{j}$ organizmalarının uygunluk değerleri hesaplanarak karşılaştırılma yapılır. Eğer 
$P_{X_{\mathrm{I}}}$ organizmasının uygunluk değeri daha iyi ise, $X_{j}$ organizması ekosistemden çıkarılarak yerine $P_{X_{\mathrm{I}}}$ organizması yerleştirilir. Böylece $X_{j}$ organizması bu birliktelikten ekosistemden ayrılarak zarar etmiş olmaktadır. Şekil 3'de Simbiyotik Organizmalar Arama algoritması verilmiştir.

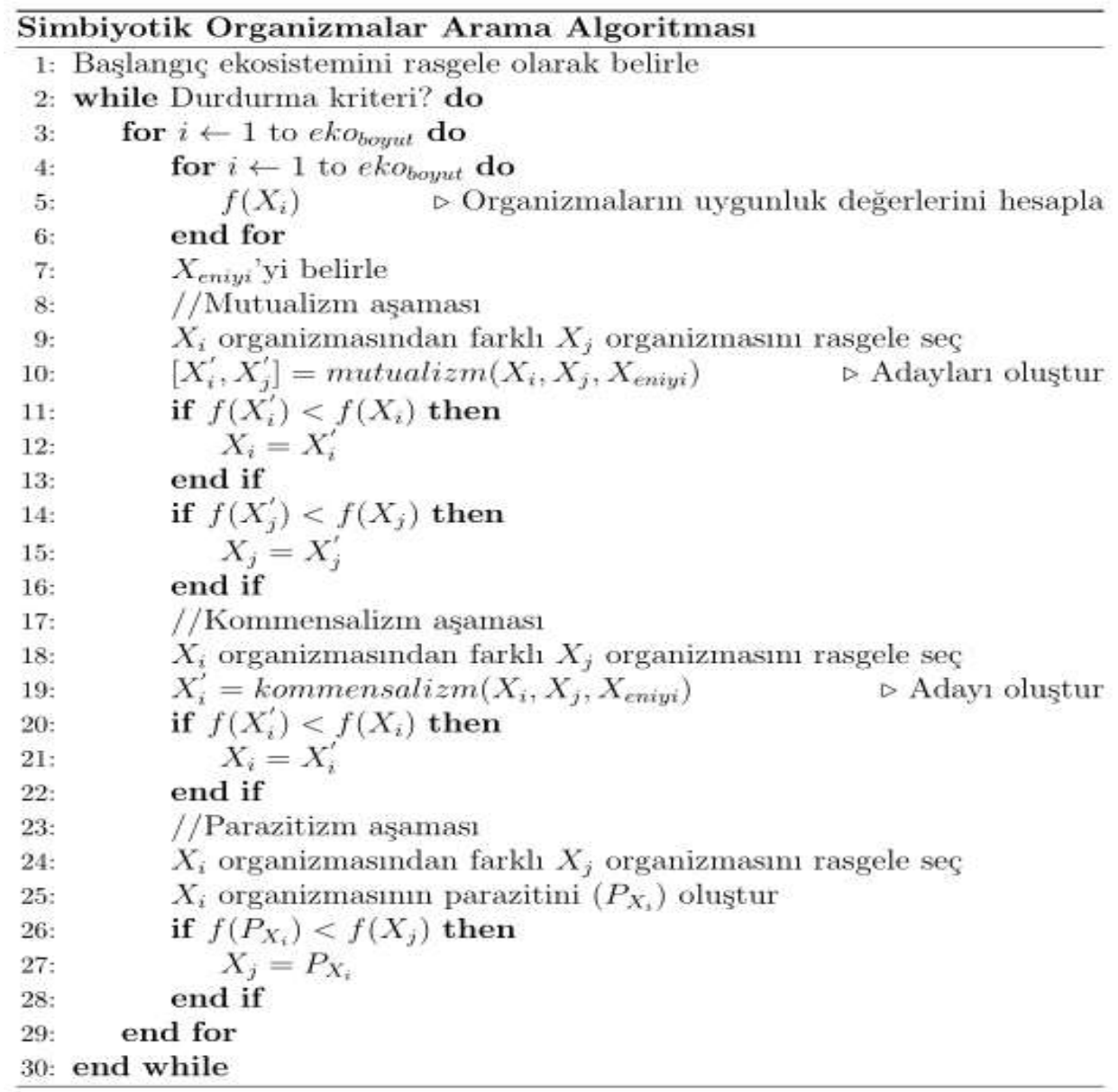

Şekil 3. Simbiyotik organizmalar arama algoritması pseudo kod

\subsection{Olușturulan model}

Çalışmada beton ağırlık barajının boyutlarının optimizasyonu amaçlanmıştır. $\mathrm{Bu}$ amaçla SOS algoritması kullanılmıș, deprem ivmesi $\left(0,0.05,0.1,0.15\right.$ ve $\left.0.2 \mathrm{~m} / \mathrm{s}^{2}\right)$ için 5 ve yükseklik değișimleri içinde ( $12 \mathrm{~m}$ den birer metre artışla $30 \mathrm{~m}$ ye kadar) de 19 farklı kombinasyon sonucu 95 adet farklı senaryo ile modelleme yapılmıştır. SOS için organizma sayısı 100 iterasyon sayısı ise 500 seçilmiştir. Dolayısı ile 4.75 milyon işlem yapılarak maliyeti minimize eden boyutlar tespit edilmeye çalışılmıştır. Betonun Elastite Modülü 27,580 Mpa, Betonun Poison Oranı 0,20, Betonun tek eksenli basınç dayanımı $35 \mathrm{Mpa}$, Betonun tek eksenli çekme dayanımı 3,5 Mpa, Betonun iki eksenli basınç dayanımı $42 \mathrm{Mpa}$,

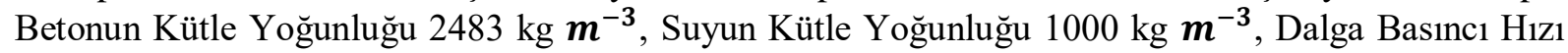
$1440 \boldsymbol{m} \boldsymbol{s n}^{\mathbf{- 1}}$, Dalga Yansıması Katsayısı 0,90 alınmıştır.

Modelde ilk olarak çalışmada sabit kabul edilen parametrelerin tanıtılmasının yanısıra çalışmanın amaçlarından olan farklı yüksekli ve deprem ivmeleri girilmiştir. Bu işlem toplam 95 adet kombinasyon için tekrarlanmıştır. Girilen bu parametreler nesneye yönelik programlama mantığı oluşturulan SOS yazılımına gönderilir. SOS içinden ise oluşturulan maliyet fonksiyonu ve kısit fonksiyonlarının bulunduğu yazılıma yönlendirilir. Bu çalışmada bu işlemler için 100 organizma ve 500 iterasyon seçilmiştir. Bu nedenle her bir senaryo için her iterasyon sonucu elde edilen 100 sonucun en iyisi ve organizmaların kendi bulduğu değerlerin en iyisi tespit edilir. Bu işlem seçilen iterasyon sayısı kadar tekrarlanır. Böylelikle her kombinasyon için 50.000 adet hesaptan en ideali doğruya en yakın sonuç olarak kabu edilir (Şekil 4). 


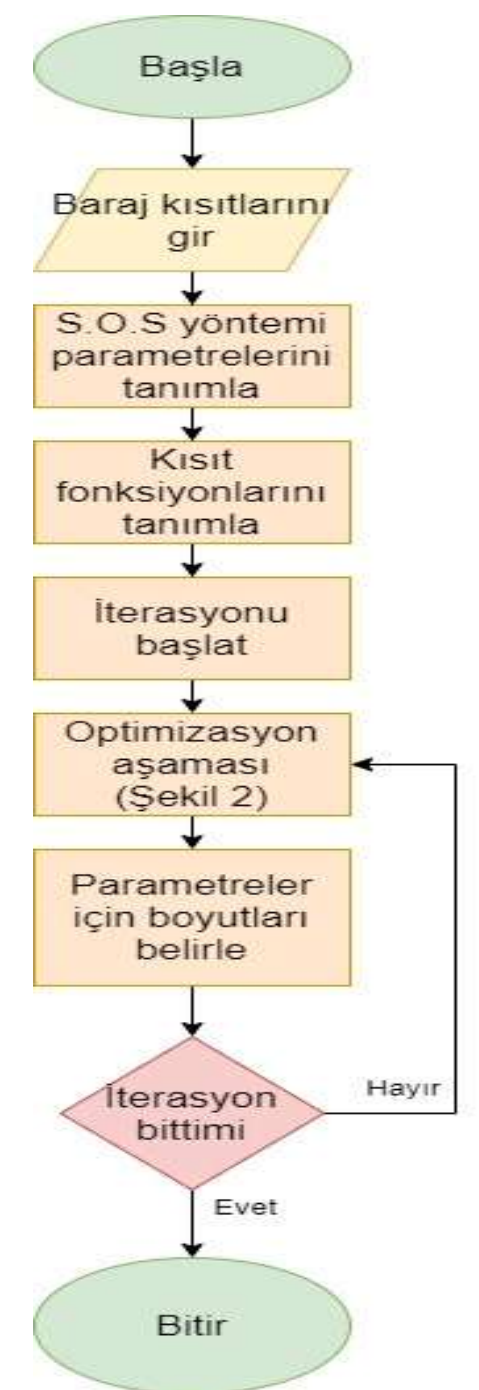

Şekil 4. Uygulanan modelin akış şeması

\section{Bulgular ve Tartışma}

Elde edilen sonuçlar irdelendiğinde baraj yüksekliğinin düşük olduğu durumlarda deprem yükündeki değişimlerin maliyetler üzerinde çok fazla bir etkisi olmadığ 1 ancak yükseklik arttıkça maliyet değişimlerinin daha çok olduğu tespit edilmiştir (Şekil 5). Ancak düşük yüksekliklerdeki artış miktarı az olmasına rağmen oransal olarak yüksek fark bulunmaktadır. Örneğin depremsiz yapılan çözümde 13 $\mathrm{m}$ lik bir barajın maliyeti $12 \mathrm{~m}$ lik bir barajın maliyetine göre $\% 26$ oranında değişmektedir. Bu değişim deprem ivmesi 0.2 seçildiğinde ise yine $\% 26$ dır. Ancak $28 \mathrm{~m}$ lik bir barajın maliyeti $27 \mathrm{~m}$ lik barajın maliyetinden \% 9 fazladır. Yani yükseklikler arttıkça maliyetin artış oranı azalmaktadır. Ancak bu artış oranı aynı deprem oranları için birbirine yakın sonuçlar vermektedir. (Tablo 3). Deprem ivmesindeki değişiklikler ise maliyetleri hangi yükseklik olursa olsun birbirine yakın oranda etkilemektedir. Örneğin depremsiz ve 0.05 ivmeli bir 12 m yüksekliğindeki baraj maliyetleri arasında $\% 11$ fark bulunmaktadır. $\mathrm{Bu}$ oran 0.15 ile 0.2 deprem ivmeleri için ise \%10.5 dir. Bu değişim yüksekğin $30 \mathrm{~m}$ ye çıktığ durumlarda da hemen hemn aynıdır (Tablo 4). Son olarak Şekil 6' da deprem ivmesi artışlarının yükseklik ile beraber maliyete olan etkisi gösterilmiştir. 


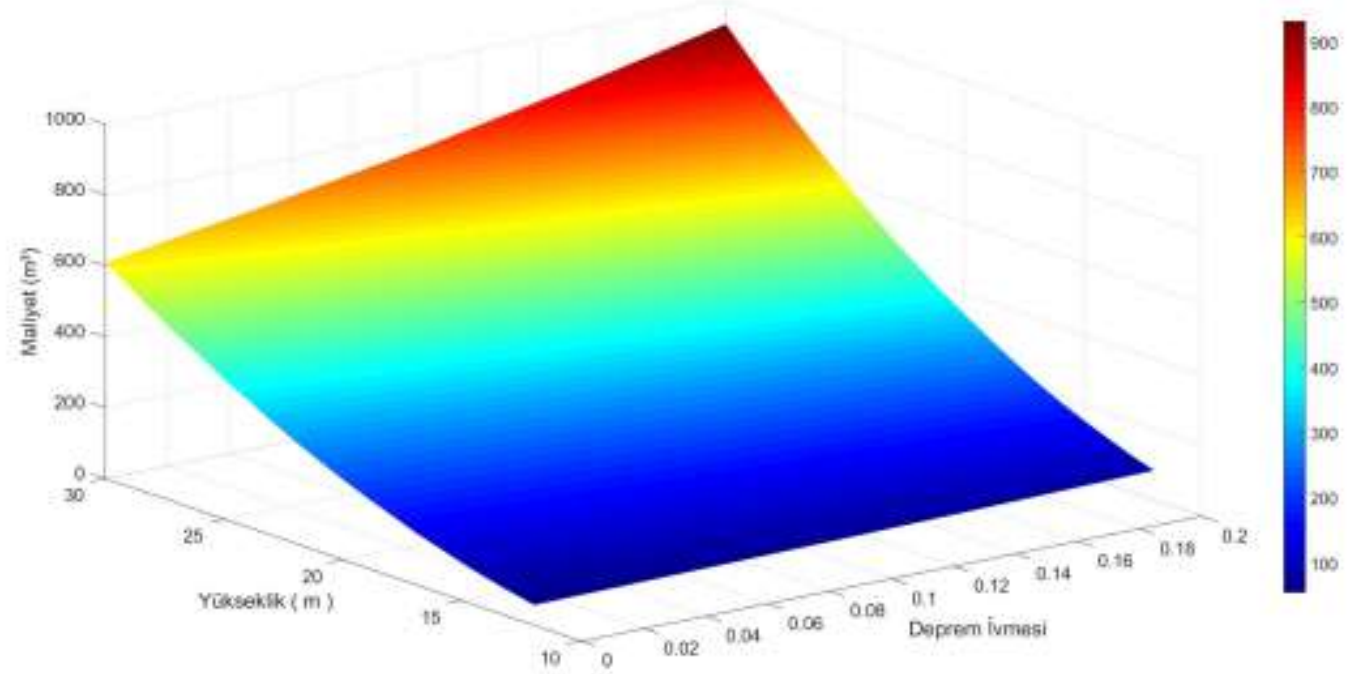

Şekil 5. Yükseklik ve deprem ivmesi değişimlerinin maliyete olan etkisi

Tablo 3. Yükseklik artışlarının bir önceki yüksekliğe ve deprem ivmesine göre etkisi

\begin{tabular}{cccccc}
\hline $\begin{array}{c}\text { Kiyaslanan } \\
\text { Yükseklik }\end{array}$ & $\begin{array}{c}\text { Deprem ivmesi } \\
0\end{array}$ & $\begin{array}{c}\text { Deprem ivmesi } \\
0.05 \\
\mathrm{~m} / \mathrm{s}^{2}\end{array}$ & $\begin{array}{c}\text { Deprem } \\
\text { ivmesi } 0.1 \\
\mathrm{~m} / \mathrm{s}^{2}\end{array}$ & $\begin{array}{c}\text { Deprem } \\
\text { ivmesi } 0.15 \\
\mathrm{~m} / \mathrm{s}^{2}\end{array}$ & $\begin{array}{c}\text { Deprem } \\
\text { ivmesi } 0.20 \\
\mathrm{~m} / \mathrm{s}^{2}\end{array}$ \\
\hline $13-12$ & $\% 26$ & $\% 25.5$ & $\% 26$ & $\% 26$ & $\% 26$ \\
$18-17$ & $\% 17$ & $\% 16$ & $\% 16.5$ & $\% 17$ & $\% 17$ \\
$24-23$ & $\% 10$ & $\% 11$ & $\% 11$ & $\% 10.5$ & $\% 10$ \\
$28-27$ & $\% 9$ & $\% 9.5$ & $\% 9$ & $\% 9$ & $\% 8.5$ \\
$30-29$ & $\% 8.5$ & $\% 9$ & $\% 8.5$ & $\% 8.5$ & $\% 8$ \\
\hline
\end{tabular}

Tablo 4. Deprem ivmesindeki değişiklerin yüksekliğe bağlı maliyete etkisi

\begin{tabular}{cccccc}
\hline Deprem ivmesi & Yükseklik & Yükseklik & Yükseklik & Yükseklik & Yükseklik \\
& $12 \mathrm{~m}$ & $17 \mathrm{~m}$ & $24 \mathrm{~m}$ & $28 \mathrm{~m}$ & $30 \mathrm{~m}$ \\
\hline $0.05-0$ & $\% 11$ & $\% 11$ & $\% 10.5$ & $\% 10.5$ & $\% 10.5$ \\
$0.01-0.05$ & $\% 11$ & $\% 10.5$ & $\% 10.5$ & $\% 10.5$ & $\% 10$ \\
$0.15-0.10$ & $\% 11$ & $\% 11$ & $\% 10.5$ & $\% 10.5$ & $\% 10.5$ \\
$0.15-0.20$ & $\% 10.5$ & $\% 10.5$ & $\% 10.5$ & $\% 10.5$ & $\% 10$ \\
\hline
\end{tabular}

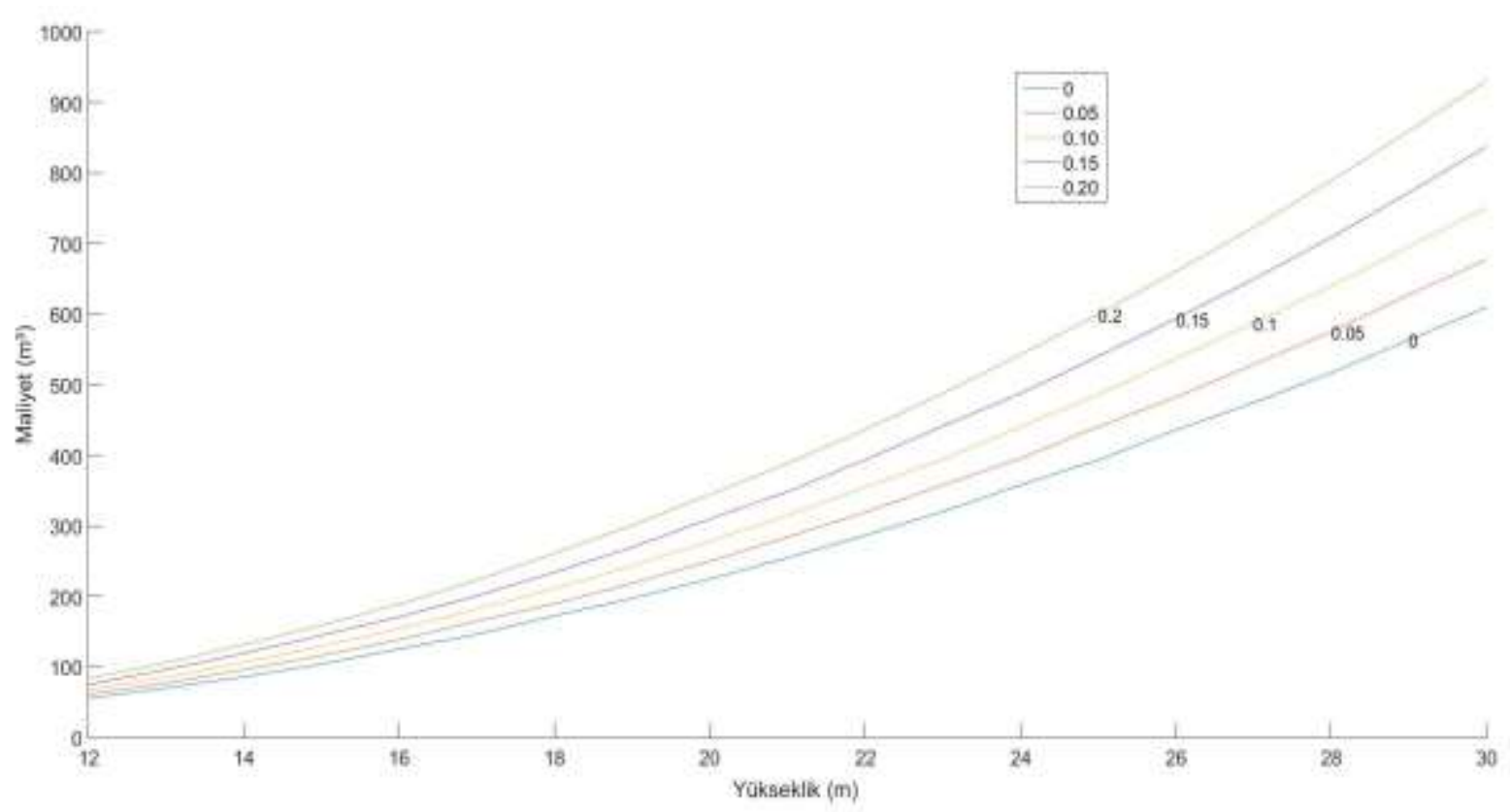

Şekil 6. Deprem ivmelerinin maliyete olan etkisi 


\section{Sonuç ve Öneriler}

Günümüzde suya olan ihtiyacın artması su kaynaklarının optimum bir şekilde projelendirilmesini ve yönetilmesini gerektirmektedir. Su kaynakları bakımından da barajlar en önemli su kaynakları yönetim elemanıdır. $\mathrm{Bu}$ çalışmada beton ağırlık barajlarının boyutlandırılması için SOS algoritması kullanılmıştır. Çalışmada 12-30 metre arasında birer metrelik değişimlerin yanı sıra $0,0.05,0.1,0.15$ ve 0.20 lik deprem ivmeleri ile 95 adet senaryonun optimum boyutları hesaplanmıştır. 95 adet farklı senaryodan elde edilen minimum maliyetleri değerleri elde edilmiştir- Buna göre, yükseklik arttıkça maliyetler artmaktadır. Artış miktarı yükseklik arttıkça daha fazla olmasına rağmen oransal olarak bakıldığında düşük yükseklikler için daha fazla artışa sahiptir (bu cümleyi daha anlaşılır bir şekilde tekrar yaz). Çalışmada elde edilen başka bir sonuç ise deprem ivmesindeki artışın yükseklikten bağımsız olarak aynı oranda etkilediğidir. Ancak miktar olarak bakıldığında yükseklik arttıkça artış (ne artışı) miktarının da arttığı görülür. Ayrıca çalışmada elde edilen 95 senaryo sonucunun herbirini elde etmek için 100 organizma ve 500 iterasyon seçilmiştir. Bu senaryoların her birinin SOS ile 100 organizma tarafindan 500 'er iterasyonla tespit edilme süresi ise ortalama 15 saniye olarak bulunmuştur. Yani problem için gerekli fizibilite çalışmaları yapılıp gerekli yükseklikler, deprem ivmesi ve gerekli parametreler seçildikten sonra maliyeti minimum-yapacak çözümler çok kısa sürede üretilebilecektir.

\section{Yazarların Katkısı}

Kemal SAPLIOĞLU gerekli tahkikler ve kısıt fonksiyonlarını optimizasyon içerisine dahil ederek farklı boyutlar için optimum sonuçları modelleme ve grafiklerin çizimi, Erdem ÇOBAN literatür taraması ve kısit fonksiyonları, Fatih Ahmet ŞENEL optimizasyon fonksiyonunu oluşturulması, Soner UZUNDURUKAN zemin emniyeti ile ilgili modellemeler konusunda katkı sağlamıştır.

\section{Çıkar Çatışması Beyanı}

Yazarlar arasında herhangi bir çıkar çatışması bulunmamaktadır.

\section{Araştırma ve Yayın Etiği Beyanı}

Yapılan çalışmada araştırma ve yayın etiğine uyulmuştur.

\section{Kaynaklar}

[1] Datta B., Chakrabarty D., Dhar A. 2011. Identification of unknown groundwater pollution sources using classical optimization with linked simulation. Journal of Hydro-Environment Research, 5 (1): 25-36.

[2] Anile A.M., Cutello V., Nicosia G., Rascuna, R., Spinella S. 2005. September. Comparison among evolutionary algorithms and classical optimization methods for circuit design problems. In 2005 IEEE Congress on Evolutionary Computation, 1: 765-772, IEEE.

[3] Saplıoğlu K., Uzundurukan S. 2019. Bilimsel çalışmalarda kullanılan bazı yapay zeka uygulamalarının ve trendlerinin incelenmesi. DÜMF Mühendislik Dergisi, 10 (1): 249-262.

[4] Geem Z.W. 2007. Optimal scheduling of multiple dam system using harmony search algorithm. In International Work-Conference on Artificial Neural Networks, 316-323, Springer, Berlin, Heidelberg.

[5] Banos R., Manzano-Agugliaro F., Montoya F.G., Gil C., Alcayde A., Gómez J. 2011. Optimization methods applied to renewable and sustainable energy: A review. Renewable and sustainable energy reviews, 15 (4): 1753-1766.

[6] Khatibinia M., Khosravi S. 2014. A hybrid approach based on an improved gravitational search algorithm and orthogonal crossover for optimal shape design of concrete gravity dams. Applied Soft Computing, 16: 223-233.

[7] Kshirsagar D.Y. 2014. Effect of variation of earthquake intensity on stability of gravity dam. J Indian Water Resour Soc, 34 (3): 1-6. 
[8] Salmasi F. 2011. Design of gravity dam by genetic algorithms. International Journal of Civil and Environmental Engineering, 3 (3): 187-192.

[9] Deepika R., Suribabu C.R. 2015. Optimal design of gravity dam using differential evolution algorithm. Iran University of Science Technology, 5 (3): 255-266.

[10] Seyedpoor S.M., Salajegheh J., Salajegheh E. 2012. Shape optimal design of materially nonlinear arch dams including dam-water-foundation rock interaction using an improved PSO algorithm. Optimization and engineering, 13 (1): 79-100.

[11] Seyedpoor S.M., Salajegheh J., Salajegheh E., Gholizadeh S. 2011. Optimal design of arch dams subjected to earthquake loading by a combination of simultaneous perturbation stochastic approximation and particle swarm algorithms. Applied Soft Computing, 11(1): 39-48.

[12] Akbari J., Ahmadi M.T., Moharrami H. 2011. Advances in concrete arch dams shape optimization. Applied Mathematical Modelling, 35 (7): 3316-3333.

[13] Hamidian D., Seyedpoor S.M. 2010. Shape optimal design of arch dams using an adaptive neurofuzzy inference system and improved particle swarm optimization. Applied Mathematical Modelling, 34 (6): 1574-1585.

[14] Seyedpoor S.M., Salajegheh J., Salajegheh E., Gholizadeh S. 2009. Optimum shape design of arch dams for earthquake loading using a fuzzy inference system and wavelet neural networks. Engineering optimization,41 (5): 473-493.

[15] Wang L., Zeng J., Xu L. 2011. A decision support system for substage-zoning filling design of rock-fill dams based on particle swarm optimization. Information Technology and Management, 12 (2): 111.

[16] Akbari J., Ahmadi M.T., Moharrami H. 2011. Advances in concrete arch dams shape optimization. Applied Mathematical Modelling, 35 (7): 3316-3333.

[17] Deepika R., Suribabu C.R. 2015. Optimal design of gravity dam using differential evolution algorithm. Iran University of Science Technology, 5 (3): 255-266.

[18] Chopra A.K. 1978. Earthquake resistant design of concrete gravity dams. Journal of the Structural Division, 104 (6): 953-971.

[19] Ozdemir G., Aydemir E., Olgun M.O., Mulbay Z. 2016. Forecasting of Turkey Natural Gas Demand Using a Hybrid Algorithm. Energy Sources Part B- Economics Planning and Policy, 11 (4): 295-302.

[20] Çatal Y., Saplığlu K. 2018. Comparison of Adaptive Neuro-Fuzzy Inference System, Artificial Neural Networks and Non-Linear Regression for Bark Volume Estimation in Brutian Pine Pinus brutia ten. Applied Ecology and Environmental Research, 16 (2): 2015-2027.

[21] Cheng M., Prayogo D. 2014. Symbiotic Organisms Search: A New Metaheuristic Optimization Algorithm. Computers and Structures, 139: 98-112.

[22] Çelik E., Öztürk N. 2017. Doğru Akım Motor Sürücüleri için PI Parametrelerinin Simbiyotik Organizmalar Arama Algoritması ile Optimal Ayarı. Bilişim Teknolojileri Dergisi, 10 (3): 311 318.

[23] Baysal Y. A., Altas I. H. 2017. Power Quality Improvement via Optimal Capacitor Placement in Electrical Distribution Systems using Symbiotic Organisms Search Algorithm. Mugla Journal of Science and Technology, 3 (1): 64-68. 